\title{
A FRAMEWORK FOR HAZARD ASSESSMENT OF DEBRIS- FLOW ACCUMULATION AREAS
}

\author{
LE, M. H. ${ }^{1,2^{*}}-$ HAN, Q. W. ${ }^{1,2}-$ FANG, C. M. ${ }^{1,2}-$ GUAN, J. Z. ${ }^{1,2}$ \\ ${ }^{1}$ State Key Laboratory of Simulation and Regulation of Water Cycle in River Basin \\ China Institute of Water Resources and Hydropower Research \\ A-1 Fuxing Rd., Haidian dist, Beijing 100038, China \\ ${ }^{2}$ Department of Sediment Research \\ China Institute of Water Resources and Hydropower Research \\ No.20 Chegongzhuang West Rd., Haidian dist., Beijing 100048, China \\ ${ }^{*}$ Corresponding author \\ e-mail: lemaohua@gmail.com; phone: +86-10-68786624; fax: +86-10-68786624 \\ (Received $5^{\text {th }}$ Dec 2018; accepted $21^{\text {st }}$ Mar 2019)
}

\begin{abstract}
An increasing demand for assessing the hazard of debris-flow accumulation areas is critical to risk management and policy implication for debris-flow hazard mitigation. In this paper, a framework for hazard assessment in debris flow-prone areas is proposed. Based on the hazard definition, debris-flow hazard is computed by its occurrence probability and disruptive intensity. Debris-flow occurrence probability is defined as a joint probability considering both hydrological and debris supply condition. Debris-flow disruptive intensity is introduced to express the inundated and impact damage of debris flow by the distribution of flow depth and velocity. The distribution is based on an extended geometric model of debris-flow fans, including the maximum length, width, and thickness (or flow depth) of debris-flow fans, and the channel outlet width. A hazard matrix, correlated to debris-flow occurrence probability and disruptive intensity, is used to map the hazard on debris-flow accumulation areas. The proposed procedure is applied to assess the debris-flow hazard on the accumulation area of Shuida gully, located in the Longchi town, Sichuan province of China. Finally, the article considers the effects of hazard maps.

Keywords: hazard recognition, debris-flow fan configuration, occurrence probability, debris-flow disruptive intensity, Shuida gully
\end{abstract}

\section{Introduction}

Debris flows are common phenomena in mountainous regions throughout the world (Coussot and Meunier, 1996). Their accumulation flooding processes always make the foothills of the landform change, and form the alluvial fans which are a preferred location for urban development owing to their good drainage conditions and gently slope. In many densely developed mountainous regions, fans provide the only readily developable land (Jakob and Hungr, 2005). Unfortunately, many fans in active mountains are prone to debris flows, which can constitute a widespread hazard to people and property (Davies and McSaveney, 2008). Therefore, there is an increasing demand for assessing the hazard of debris-flow accumulation areas, which is critical to risk management and policy implication for debris-flow hazard mitigation.

According to the International Union of Geological Sciences definition (IUGS, 1997), a hazard in a given point on an alluvial fan is defined as the probability that a debris flow of a defined intensity will occur. Based on this definition, the hazard assessment mainly includes two parts: one is the debris-flow occurrence probability related to its basin characteristics and hydrological conditions, the other is the debrisflow intensity described by means of variables characterizing its destructive power. 
Over the past few decades, the debris-flow hazard assessment has been generally carried out either by using empirical approaches or applying physical and numerical methods. The empirical models (Okunishi and Suwa, 2001; Iverson, 2014; Rickenmann, 2016) are based on few parameters and consequently allow generalized conclusions only. However, they generally offer a readily applicable and verifiable approach. The most common empirical relationships estimate the maximum run-out distance of debris flow. In recent years, data mining has been utilized for assessing debris flow hazards (Lin et al., 2012; Liang et al., 2012). With the development of rheological and physical-mathematical based modeling of debris flows, numerical techniques and geographical information science, quantitative approaches are widelyused to assess the hazard of debris-flow. For example, Wei et al. (2003) simulated the movement process of debris flow out of the outlet, and established the momentum model for debris flow risk zoning. Liu and Huang (2006) introduced the concept of separating the boundary layer and the main flow in fluid mechanics to debris flows, and developed a numerical program for field application on hazard area mapping. Tsai et al. (2011) considered large-scale debris flow simulations in various volumes at the same area by using the DEBRIS-2D numerical program for hazard assessment.

Taking into account the triggering, propagation and stoppage of debris flows, Calvo and Savi (2009) applied a Monte Carlo procedure to quantify debris flow hazard. De Scally et al. (2010) conducted discriminant analysis for identifying controls on fan depositional processes, and implications for the assessment of debrisflow hazard on fans. Hürlimann et al. (2008) reviewed various different run-out and intensity calculation methods and discussed their implication for generating debrisflow hazard maps. In quantitative approaches, Guzzetti et al. (2005) proposed a probabilistic model to determine landslide hazard at the basin scale. Based on debris supply conditions, the basins where debris flows occur can be classified as either supply-limited (or weathering-limited) or supply-unlimited (or transport-limited) (Glade, 2005; Jakob et al., 2005). However, the existing debris-flow occurrence probability calculation methods were generally on the assumption of unlimited sediment availability, neglecting the requirement of a significant recharge period prior to each debris flow event. In addition, the determination of debris-flow magnitude and intensity is also necessary during the hazard assessment (Jakob and Hungr, 2005). Typically, the characteristic parameters such as area inundated, maximum flow velocity, and maximum flow depth are related.

In this study, a framework for hazard assessment of debris-flow accumulation areas was developed. Four key components of this framework were discussed: (i) the debris-flow occurrence probability was estimated by combining the critical hydroclimatic thresholds and debris supply conditions; (ii) the fan configurations were classified as complete, partial and unformed types, and an extended geometric model of debris-flow fans was provided for hazard assessment; (iii) the disruptive intensity was introduced to express the inundated and impact damage of debris flows; (iv) the debris-flow occurrence probability and destructive power were correlated in a hazard matrix which can represent hazard qualitatively by hazard degree classes or quantitatively by a value ranging from zero to unity. Finally, the developed framework was applied to evaluate the debris-flow hazard on the accumulation area of Shuida gully, located in the Longchi town, Sichuan province of China. 


\section{Methods and Materials}

\section{Methods}

The framework for hazard assessment of debris-flow accumulation areas includes the following steps (Fig. 1):

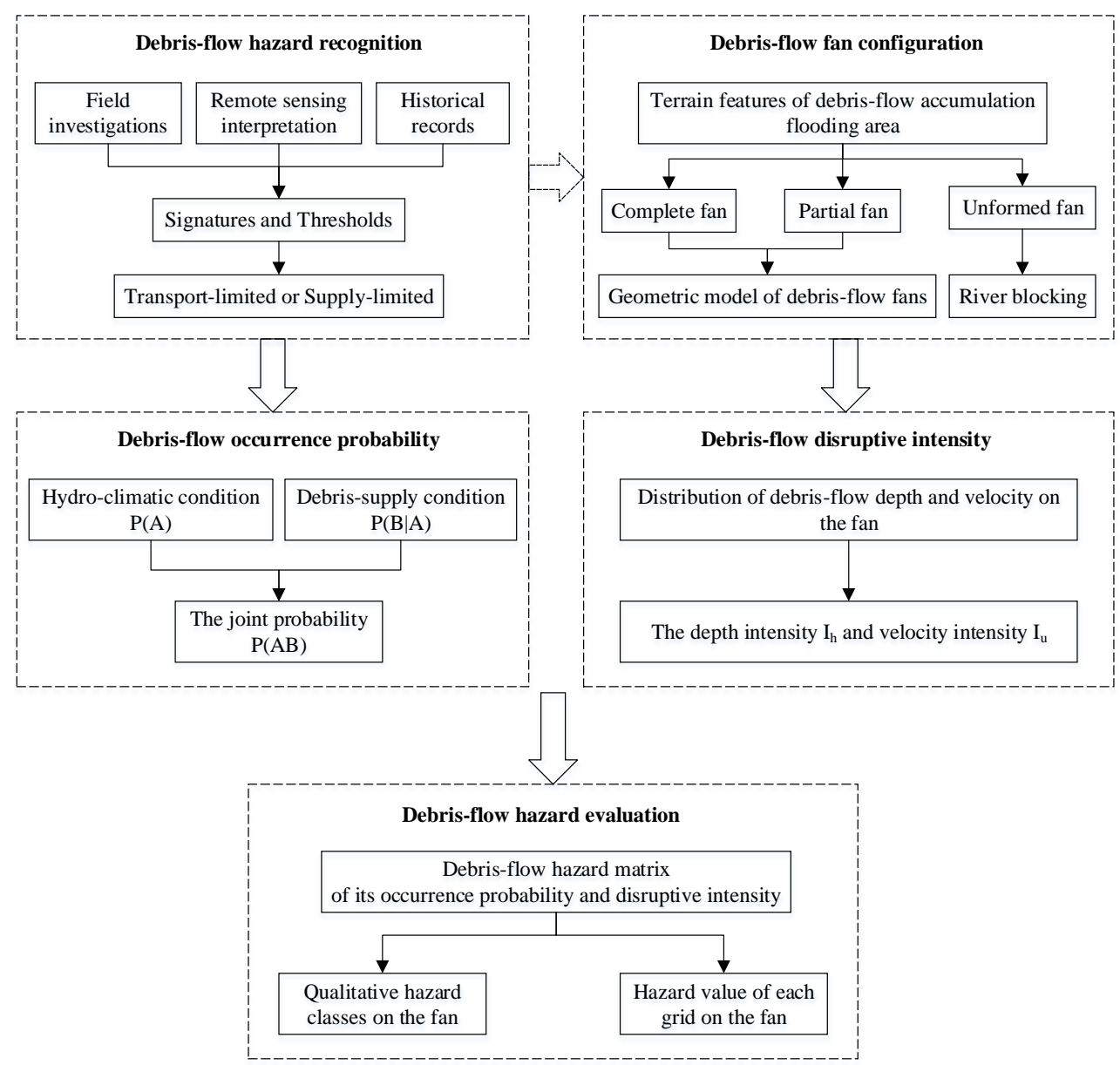

Figure 1. The framework for hazard assessment of debris-flow accumulation areas

- Debris-flow hazard recognition is the first, and possibly most important segment. The causes of debris flows, and their behavior once initiated, are known in outline but poorly understood to date (Iverson, 1997; Takahashi, 2009). However, it is clear that a debris flow occurrence requires large volumes of sediment to be available, either on slopes or in a stream channel, and steep slopes to allow rainfall and/or stream-flow of sufficient magnitude to mobilize the sediment (Welsh and Davies, 2011). Thus, we propose a reference method for debris-flow hazard identification based on its occurrence signatures or thresholds (Table 1). Additionally, it is necessary for the following probability estimation to divide gullies into transport-limited and supply-limited by field investigation of catchment characteristics.

- Debris-flow occurrence probability is a function of the critical hydro-climatic thresholds and debris supply conditions. Therefore, the authors defined a joint 
probability to estimate the hazard occurrence probability considering both hydrological and geomorphic characteristics.

- Debris-flow fan configuration is the basis of hazard evaluation. According to the different terrain features of debris-flow accumulation flooding area, the fan configurations may unfold in various spatial patterns. In order to establish a geometric model of debris-flow fans for the following calculations, the fan configurations are classified as complete, partial and unformed types, and an extended geometric model of debris-flow fans is provided.

Table 1. The reference method for debris-flow hazard recognition

\begin{tabular}{c|c|c}
\hline Criterion & Description & References \\
\hline Signatures & $\begin{array}{c}\text { Steep channel } \\
\text { Narrow channel, small width-to-depth ratio } \\
\text { Semi-circular to U-shaped channel }\end{array}$ & \\
& $\begin{array}{c}\text { Accumulation of unconsolidated sediment in the channel } \\
\text { Channel scoured to bedrock, or filled with coarse rock-fall debris with } \\
\text { high hydraulic conductivity (supply-limited) }\end{array}$ & $\begin{array}{c}\text { Meyer et al. (2014); } \\
\text { Jakob and Hungr } \\
\text { (2005) }\end{array}$ \\
& $\begin{array}{c}\text { Scour marks, mud-lines and debris impact scars on the trees well above the } \\
\text { flood limit }\end{array}$ & $\begin{array}{c}\text { Inverse grading of fan or levee deposits } \\
\text { Coarse deposits beyond the channel on the fan } \\
\text { Poorly sorted or imbricated deposits on the fan }\end{array}$ \\
$\begin{array}{c}\text { Melton ratio } \mathrm{R}>0.5 \\
\text { Watershed length WL } \leq 2.7 \mathrm{~km}\end{array}$ & $\begin{array}{c}\text { Wilford et al. (2004); } \\
\text { Welsh and Davies } \\
\text { (2011); Yu et al. } \\
\text { (2014) }\end{array}$ \\
\hline
\end{tabular}

- Dividing debris-flow fans into many grids with equal area, we can evaluate hazard of each grid by the disruptive intensity, which is introduced to express the inundated and impact damage of debris flow by the distribution of flow depth and velocity.

- Debris-flow occurrence probability and destructive power are correlated in a hazard matrix which can represent hazard qualitatively by hazard degree classes or quantitatively by a value ranging from zero to unity. For practical use, administrations always use qualitative hazard classes to better correlate with building codes and urbanization plans (Raetzo et al., 2002). However, quantitative methods have their advantages of objectivity.

\section{Debris-flow occurrence probability}

Debris flow initiation requires steep slopes, availability of erodible sediments, and a storm of sufficient magnitude. Thus, we apply a joint probability $P(A \cap B)$ to calculate the probability of debris-flow occurrence using Equation 1:

$$
P_{H}=P(\mathrm{~A} \cap \mathrm{B})=P(\mathrm{~B} \mid A) \times P(A)
$$

where $P_{H}$ is the debris-flow occurrence probability; A represents the local hydroclimatic condition or rainfall exceeding the critical value; $B$ represents the availability of erodible sediments under the given slope channel; $(B \mid A)$ indicates the occurrence of $\mathrm{B}$ under the triggering condition $\mathrm{A} ; \mathrm{A} \cap \mathrm{B}$ indicates the simultaneous occurrence of $\mathrm{A}$ and $\mathrm{B}$; and $\mathrm{P}$ is the event occurrence probability. 
As an approximation, rainfalls can be considered as independent random-point events in time (Cowpertwait et al., 1996), the occurrence probability of a rainfall during a period of $n$ years can be estimated using the binomial equation:

$$
P(A)=1-(1-1 / T)^{n}
$$

where $\mathrm{T}$ is the return period of rainfalls. It can be obtained from a historical catalogue of local rainfalls or from the local hydrological handbook.

To determine the occurrence probability of sediment entrainment under condition A, it is necessary to discuss the debris supply condition and the magnitude (or transport capacity) of A in a given basin. In transport-limited gullies, abundant readily entrainable sediment is present, and whenever a rainfall of sufficient magnitude occurs, a debris flow will result. On the contrary, in supply-limited gullies, the volume of entrainable sediment is limited, and a rainfall of sufficient magnitude may not initiate a debris flow unless enough sediment is available (Brayshaw and Hassan, 2009). In the conceptual model for supply-limited gullies (Glade, 2005), an extrinsic hydro-meteorological threshold is not a sufficient condition, but an intrinsic sediment recharge threshold must be reached for debris flows to occur. Otherwise, there is an inherent danger of overestimating debris-flow occurrence when considering rainfall events only. Generally, rainfall will not necessarily trigger debris flows but floods or hyper-concentrated flows. The sediment recharge threshold is related to channel recharge rate, which can be determined by knowledge of debris storage and the elapsed time since the last debris flow in the basin (Jakob et al., 2005).

Consequently, we set the conditional probability for quantitative hazard assessment as: $\mathrm{P}(B \mid A)=1$ in transport-limited basins; and $\mathrm{P}(B \mid A)$ values in the interval $(0,1)$ in supply-limited basins. Owing to the difficulty in evaluating sediment recharge rate in gullies, we refer the existing quantitative study on the effect of geological conditions on debris-flow occurrence (Yu et al., 2014), and roughly estimate $\mathrm{P}(B \mid A)=0.6$ in supplylimited basins where weathering are strong and precipitation are abundant, while $\mathrm{P}(B \mid A)=0.2$ elsewhere.

\section{Debris-flow fan configuration}

Delimiting the spatial extent of potential damage from debris flows relies on understanding of the fan evolution, which is mainly governed by the terrain features of debris-flow accumulation flooding areas, and the physical properties of debris flows, such as rheology, sediment concentration. Since the different depositing conditions for debris flows, fan configurations may unfold in various surficial patterns. We categorize the fan configurations as complete, partial and unformed types. The latter two types always result in river blocking, and the last one may fail to form a fixed shape. Therefore, the authors only proposed a geometric model for the first two types.

Generally, natural debris-flow fans cannot be easily sorted in a precise and uniform shape. In the past, the fan shape has been represented by a semi-circle or semi-ellipse (Tsai, 2006; Takahashi, 2014), which assumes the maximum width of debris-flow fan locates at the outlet of the main channel. In other words, the circumferential angle corresponding to the plane of debris-flow fan is always equal to $90^{\circ}$. To further promote the utilization of the geometric model of debris-flow fans, the authors assumed debrisflow fans as a sector planar, where the effect of hydraulic structures, roads, and buildings on the flowing direction is not considered, and the path of the flow 
downstream from the mouth is straight. In this study, the maximum length $l_{m}$, width $b_{m}$, and thickness (or flow depth) $h_{m}$ of debris-flow fan, and the channel outlet width $b_{0}$ are used to derive the geometric model for debris-flow fans, as shown in a rectangular Cartesian coordinate system (Fig. 2). For practical use, the channel outlet width can be measured by field investigation, and other parameters can be estimated by empirical formulas (Table 2). Additionally, if debris flows occur under the same formation conditions, the four parameters can be valued by the existing field survey record.

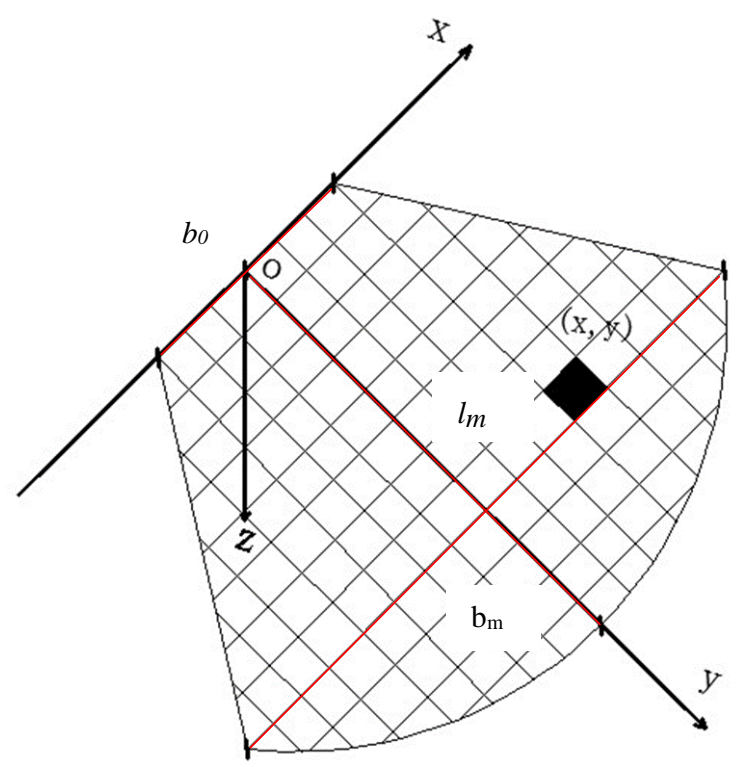

Figure 2. The coordinate system of the debris-flow fan (The origin is at the outlet center, $x$ is parallel to the transverse section, y points down the fan slope, and $z$ points into the slope, normal to the $x$-y plane)

Table 2. Empirical formulas for estimation of the maximum length, width, and thickness of the debris-flow fan

\begin{tabular}{l|c|c}
\hline \multicolumn{1}{c|}{ Formulations } & Scope & References \\
\hline$l_{m}=15 V_{c}^{1 / 2}$ & Worldwide & Rickenmann (1999) \\
\hline$l_{m}=-143.3387+29.8536 \ln V_{c}$ & $\begin{array}{c}\text { The slope of accumulation area is } \\
\text { about } 5^{\circ} ; \text { debris flow density is } \\
b_{m}=-149.0417+25.6293 \ln V_{c}\end{array}$ & Liu et al. (1993) \\
$h_{m}=0.7067+0.0001 \ln V_{c}$ & Wenchuan earthquake area & Tang et al. (2012) \\
\hline$l_{m}=0.36 A^{0.06}+0.03\left(V_{L}-H\right)^{0.54}-0.18$ & $0.40 A^{0.09}+0.04\left(V_{L}-H\right)^{0.35}-0.23$ & $b_{m}=0.40$
\end{tabular}

Based on the above coordinate system, the corresponding circumferential angle of the fan plane is firstly derived:

$$
\theta=\arcsin \frac{b_{m}}{\sqrt{4 l_{m}{ }^{2}+b_{0}{ }^{2}}}-\arctan \frac{b_{0}}{2 l_{m}}
$$

where $0^{\circ}<\theta<90^{\circ}$. 
Then, the fan shape can be described mathematically by the width of each transverse section, the calculation can be expressed as follows:

$$
\mathrm{b}=\left\{\begin{array}{cc}
b_{0}+2 y \tan \theta & 0 \leq y \leq \frac{b_{m}-b_{0}}{2} \cot \theta \\
\frac{\sqrt{b_{m}^{2}-\left(2 y \sin \theta+b_{0} \cos \theta\right)^{2}}}{\sin \theta} & \frac{b_{m}-b_{0}}{2} \cot \theta<y \leq l_{m}
\end{array}\right.
$$

where $y$ is the longitudinal axis value of each grid center.

When $\theta=90^{\circ}$, the fan shape is a semi-circle or semi-ellipse, whose width will be calculated as:

$$
\mathrm{b}=b_{m} \sqrt{1-\left(\frac{y}{l_{m}}\right)^{2}}
$$

According to the experimental results (Tsai, 2006; Takahashi, 2014), the nondimensional longitudinal profile of fans can be approximated using a half-Gaussian curve, the calculation can be expressed as:

$$
\frac{z_{c}}{h_{m}}=\exp \left[-\frac{1}{2 C_{L}{ }^{2}}\left(\frac{y}{l_{m}}\right)^{2}\right]
$$

The non-dimensional transverse profile can be approximated by a Gaussian curve:

$$
\frac{z}{z_{c}}=\exp \left[-\frac{1}{2 C_{T}^{2}}\left(\frac{x}{b}\right)^{2}\right]
$$

where $Z_{\tau}$ denotes the thickness at the center point $(0, y)$ along the longitudinal axis; $\mathrm{Z}$ represents the thickness at any grid $(\mathrm{x}, \mathrm{y})$; and $C_{L}, C_{T}$ are empirical coefficients, given approximately as 0.389 and 0.211 .

Thus, if $l_{m}, b_{m}, h_{m}, b_{0}$ are given, we can obtain the three-dimensional topography of debris-flow fans using Equations $3 a-3 e$.

\section{Debris-flow disruptive intensity}

In order to describe the damage degree of debris flow, a relatively disruptive intensity is introduced:

$$
I_{\xi}=\frac{\xi(x, y)}{\xi_{m}}
$$

where $I_{\xi}$ is the debris-flow disruptive intensity represented by variable $\xi$ characterizing the debris-flow destructive power; $\xi(\mathrm{x}, \mathrm{y})$ is the variable value of each grid on the fan; and $\xi_{m}$ is the maximum. For expressing the inundated and impact damage of debris flow, $\xi$ can be considered as flow depth and velocity.

United Equations $3 a-3 e$, the inundated damage intensity can be deduced: 


$$
I_{h}=\left\{\begin{array}{cc}
\exp \left[-\frac{y^{2}}{2 C_{L}^{2} l_{m}^{2}}-\frac{x^{2}}{2 C_{T}^{2}\left(b_{0}+2 y \tan \theta\right)^{2}}\right] & 0 \leq y \leq \frac{b_{m}-b_{0}}{2} \cot \theta \\
\exp \left[-\frac{y^{2}}{2 C_{L}^{2} l_{m}^{2}}-\frac{x^{2} \sin ^{2} \theta}{2 C_{T}^{2}\left(b_{m}^{2}-\left(2 y \sin \theta+b_{0} \cos \theta\right)^{2}\right)}\right] & \frac{b_{m}-b_{0}}{2} \cot \theta<y \leq l_{m}
\end{array}\right.
$$

When $\theta=90^{\circ}$, the intensity can be calculated as:

$$
I_{h}=\exp \left[-\frac{y^{2}}{2 C_{L}{ }^{2} l_{m}{ }^{2}}-\frac{x^{2} l_{m}{ }^{2}}{2 C_{T}{ }^{2} b_{m}{ }^{2}\left(l_{m}{ }^{2}-y^{2}\right)}\right]
$$

Considering the impact damage intensity, the distribution of velocity on the fan should be known. The authors assumed the debris-flow depositing processes in the mainstream line (along the maximum length) are uniform deceleration motion, and the attenuation processes of flow velocity in the transverse section are linear with the distance from the mainstream line, which will be decelerated to zero at the edge of the fans. Thus, the flow velocity at any grid $(x, y)$ on the fan can be expressed as:

$$
\mathrm{u}(x, y)=\frac{b-2|x|}{b} \times u_{m} \times \sqrt{1-\frac{y}{l_{m}}}
$$

where $u_{m}$ is the maximum of flow velocity.

According to Equation 4, the impact damage intensity can be expressed as:

$$
I_{u}=\frac{b-2|x|}{b} \times \sqrt{1-\frac{y}{l_{m}}}
$$

As a result, debris-flow disruptive intensity can be obtained by $l_{m}, b_{m}, b_{0}$, including two empirical coefficients $C_{L}, C_{T}$.

\section{Debris-flow hazard evaluation}

Based on the above derivation, debris-flow hazard of each unit on the fan can be computed as:

$$
P(\xi)=P_{H} \times I_{\xi}
$$

where $P(\xi)$ is a probability function of variable $\xi$ characterizing the debris-flow destructive power.

According to the definition of hazard, the necessary parameters at each grid in a hazard map are occurrence probability and disruptive intensity of debris flows (Hürlimann et al., 2008). Thus, these two parameters are correlated in a hazard matrix which can represent hazard qualitatively by hazard degree classes or quantitatively by a value ranging from zero to unity. An example of a debris-flow hazard matrix is given in Table 3.

In this hazard matrix, the debris-flow occurrence probability is classified into two groups. When the occurrence probability is smaller, the alluvial fan scale may be larger, and its disruptive intensity is greater. Therefore, we rank hazard degree classes with different intensity intervals in the groups. 
Table 3. Example of debris-flow hazard matrix

\begin{tabular}{|c|c|c|c|c|}
\hline Class & $\begin{array}{c}\text { Occurrence } \\
\text { probability, } P_{H}\end{array}$ & $\begin{array}{c}\text { Disruptive intensity, } \\
I_{\xi} \\
\end{array}$ & $\begin{array}{c}\text { Occurrence } \\
\text { probability, } P_{H}\end{array}$ & \begin{tabular}{|c|} 
Disruptive intensity, \\
$I_{\xi}$ \\
\end{tabular} \\
\hline Very high & \multirow{4}{*}{$0.01,1$} & {$[0.7,1]$} & \multirow{4}{*}{$(0,0.01)$} & {$[0.5,1]$} \\
\hline High & & {$[0.5,0.7)$} & & {$[0.2,0.5)$} \\
\hline Medium & & {$[0.2,0.5)$} & & {$[0,05,0.2)$} \\
\hline Low & & {$[0,0.2)$} & & {$[0,0.05)$} \\
\hline
\end{tabular}

\section{Materials}

The proposed framework is applied to evaluate the debris-flow hazard on the accumulation area of Shuida gully, located in the Longchi town, Sichuan province of

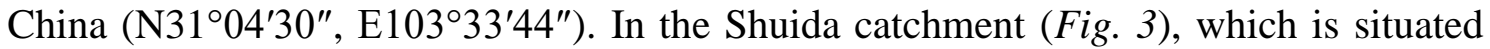
in the Wenchuan earthquake area, a debris flow was triggered by a rainstorm on 13 August 2011.
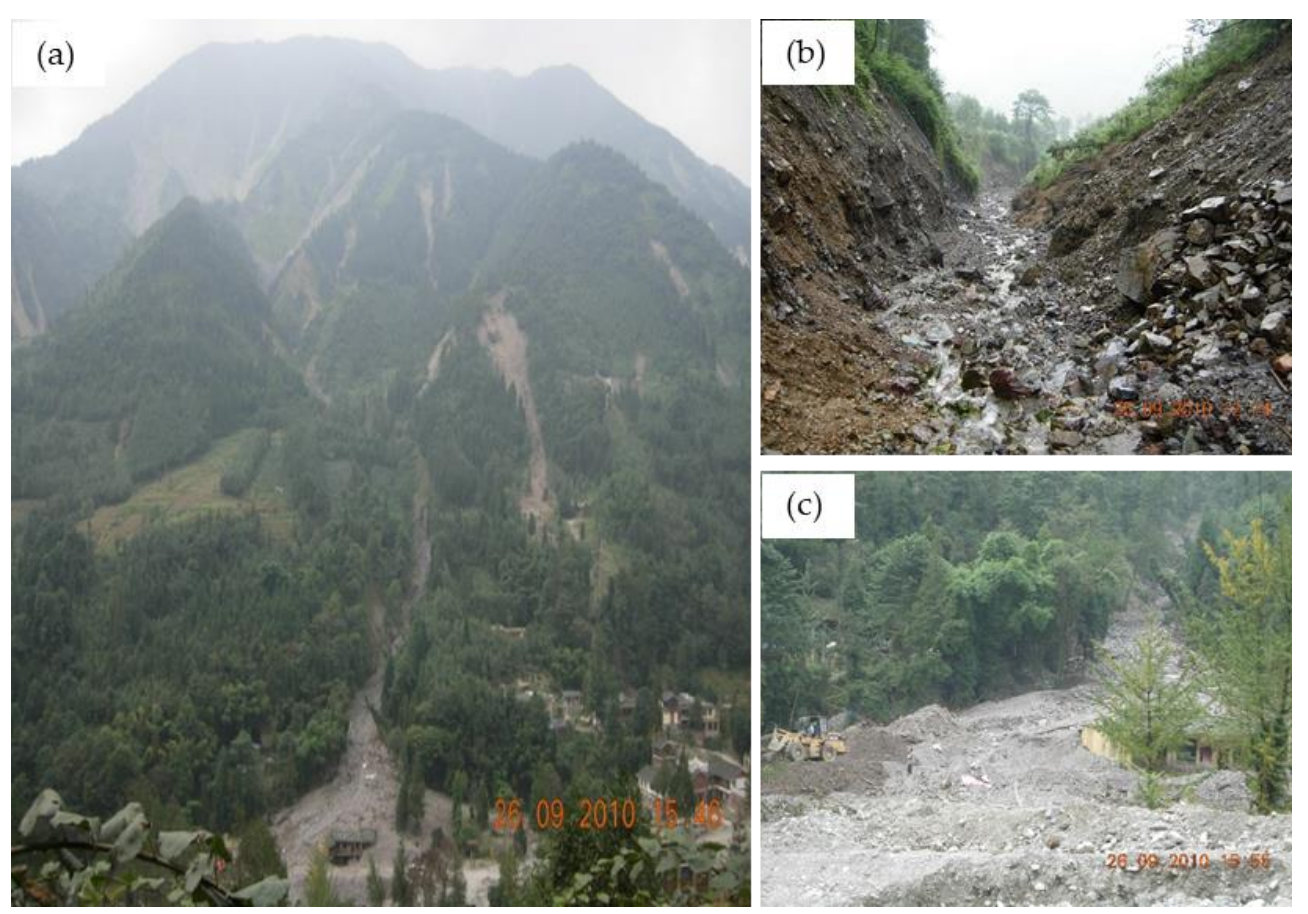

Figure 3. (a) Photography showing the whole Shuida catchment and co-seismic landslides developed upslope; (b) The debris-flow scoured channel; (c) The deposited fan

Field investigations indicated that the gully was transport-limited, where abundant loose materials deposited after the earthquake. According to the local hydrological handbook, the return period of the rainstorm was 50 years. The $0.5 \mathrm{~km}^{2}$ catchment has $650 \mathrm{~m}$ of relief with a mean catchment slope of 0.20 . The necessary parameters for hazard assessment of debris flow are reported in Table 4. 
Table 4. Parametric values used in the hazard assessment

\begin{tabular}{c|c|c|c|c}
\hline$b_{0}(m)$ & $b_{m}(m)$ & $l_{m}(m)$ & $h_{m}(m)$ & $u_{m}(m / s)$ \\
\hline 35 & 154 & 180 & 7 & 5 \\
\hline
\end{tabular}

\section{Results}

According to the above methods, the annual exceedance probability of Shuida gully debris flow is 0.02 . The fan plane can be described by the width of each transverse section, which is deduced from Equations $3 a-3 b$, as follows:

$$
\mathrm{b}=\left\{\begin{array}{cc}
35+0.71 y & 0 \leq y \leq 166.67 \\
\frac{\sqrt{23716-(0.67 y+32.96)^{2}}}{0.34} & 166.67<y \leq 180
\end{array}\right.
$$

According to Fig. 4, the actual deposited area can be measured at $22832 \mathrm{~m}^{2}$, and the calculated area is $17118 \mathrm{~m}^{2}$, while the overlapping area is $17068 \mathrm{~m}^{2}$. Thus, the accuracy of the proposed geometric model is $75 \%$, and it can be calculated as:

$$
A_{m}=\frac{s_{b}}{s_{n}} \times \frac{s_{b}}{s_{m}}
$$

where $A_{m}$ is the accuracy of model; $S_{a}$ is the actual deposited area; $S_{b}$ is the overlapping area; and $S_{m}$ is the area calculated by the above geometric model of debris-flow fan.

Due to the fan partially unfolding, the accuracy of the model may be affected. However, the calculated area basically overlaps the actual accumulation area. In the calculated area, the fan domain is divided into many grids with equal area of $5 \mathrm{~m} \times 5 \mathrm{~m}$, and the debris-flow disruptive intensity of each grid was calculated by Equations $5 a$ and $6 b$. The calculation process was carried out on ArcGIS 10.2. The final hazard maps are shown in Fig. 4.
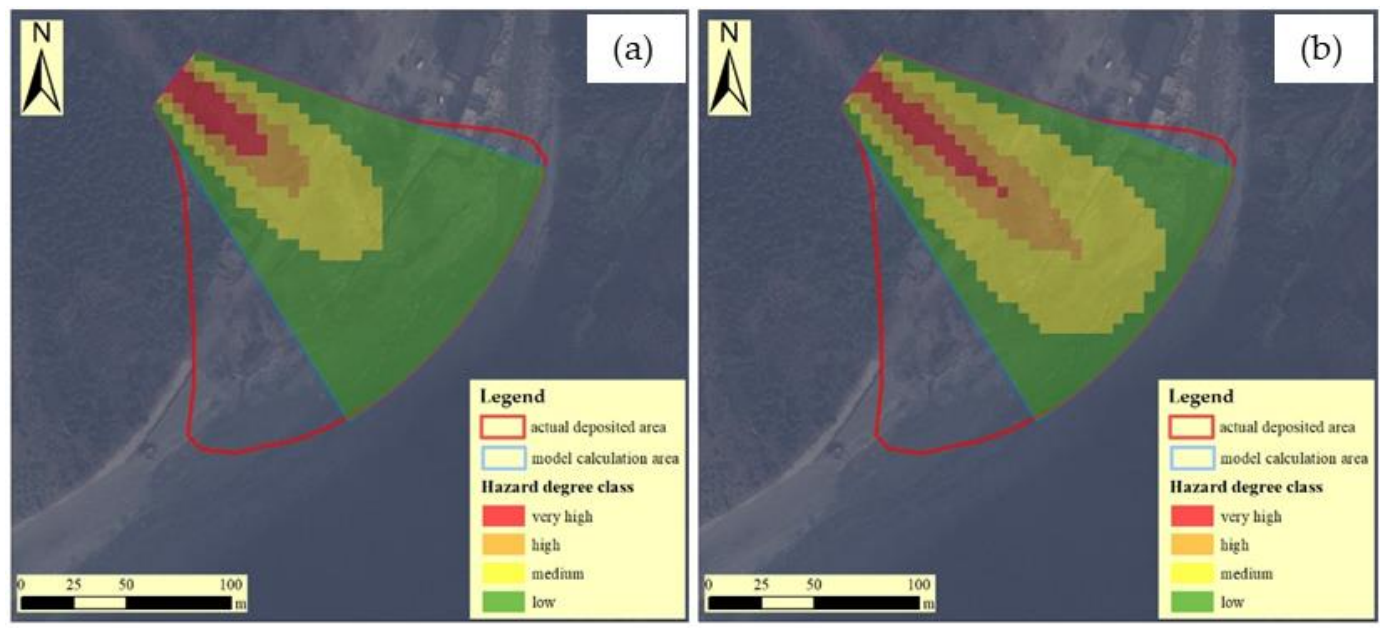

Figure 4. Hazard map of Shuida gully debris flow according to the proposed methods depending on (a) Flow depth; (b) Flow velocity 
According to Fig. 4(a), the area proportion of hazard grades from very high to low is $4.9 \%, 5.8 \%, 18.2 \%$, and $71.1 \%$, respectively. The proportion of flow depth greater than $1.4 \mathrm{~m}$ is $28.9 \%$, which represents the inundated damage of Shuida gully debris flow. Fig. 4(b) shows the debris-flow impact damage, and the proportion of flow velocity greater than $1 \mathrm{~m} / \mathrm{s}$ is $54.9 \%$.

\section{Discussion}

The developed methods appear useful and efficient for mapping the hazard on debris-flow accumulation area. These methods allow to emphasize and estimate the hazard component of debris flow, including the calculations of debris-flow occurrence probability and disruptive intensity. The hazard matrix, correlated to debris-flow occurrence probability and destructive power, can satisfy different evaluation requirements by hazard degree classes or by a value ranging from zero to unity. Meanwhile, the proposed framework, including five steps in a quantitative way to evaluate hazard of each grid on debris-flow fans, also points out some directions to be further studied:

- During the recognition of debris-flow hazard, it is useful to distinguish the debris supply condition of gullies. In supply-limited gullies, the importance of the recharge rate of sediments that may influence the frequency of occurrence and the magnitude of debris flows should be investigated. Moreover, the appropriate and reliable quantitative methods are expected to put forward for debris-flow hazard recognition.

- The conditional probability $\mathrm{P}(B \mid A)$ is related to the triggering mechanism of debris flow. So it is important to introduce the initiation law of sediment under different hydro-climatic conditions, and establish the relationship between the conditional probability and the triggering condition of debris flow.

- The fan-forming process is difficult to be described mathematically in a precise shape, owing to the diversity of the terrain features of debris-flow accumulation areas and the complexity of the physical properties of debris flows. Although the developed geometric model of debris-flow fans further promotes the existing model, a more reliable numerical simulation is still regarded as a better method. Thus, the depositing processes of debris flows should be studied by governing equations for more accurate simulation of debris-flow fans.

- The above disruptive intensity is a relative value, which should be measured combined with its maximum. Other variables such as flow discharge, impact force, or momentum may also be available as indicators characterizing debris-flow destructive power.

\section{Conclusion}

According to the hazard definition, a framework for hazard assessment of debrisflow accumulation areas was proposed, including the calculations of debris-flow occurrence probability and disruptive intensity. A joint probability was defined to estimate debris-flow occurrence probability considering both hydrological and geomorphic characteristics, which was carried out on dividing basins into transportlimited or supply-limited by debris-flow occurrence signatures or thresholds. A relatively disruptive intensity was introduced to describe the damage degree of debris 
flows by the distributions of flow depth and velocity. The distributions were obtained by an extended geometric model of debris-flow fans, and a hypothesis of uniform deceleration motions on fans.

The application for mapping the hazard on Shuida alluvial fan indicates that the developed geometric model can reflect the debris-flow accumulation flooding area, and the hazard evaluation by the given hazard map can show the inundated and impact damage of the debris flow in reality. Meanwhile, a numerical simulation, considering accumulation processes of debris flows, will be inspired in the future.

Acknowledgements. This work was funded by (1) National Key R\&D Plan (Grant No. 2017YFC0405301); (2) International S\&T Cooperation Program of China (Grant No. 2015DFR70980); (3) Scientific Program of China Institute of Water Resources and Hydropower Research (Grant No. SE0145B792017), and (4) Open Research Fund of State Key Laboratory of Simulation and Regulation of Water Cycle in River Basin, China Institute of Water Resources and Hydropower Research (Grant No. SKL2018ZY07). The materials were obtained with the help of Prof. Tang Chuan from State Key Laboratory of Geohazard Prevention and Geoenvironment Protection (Chengdu University of Technology).

\section{REFERENCES}

[1] Brayshaw, D., Hassan, M. A. (2009): Debris flow initiation and sediment recharge in gullies. - Geomorphology 109: 122-131.

[2] Calvo, B., Savi, F. (2009): A real-world application of Monte Carlo procedure for debris flow risk assessment. - Computers \& Geosciences 35(5): 967-977.

[3] Coussot, P., Meunier, M. (1996): Recognition, classification and mechanical description of debris flows. - Earth-Science Reviews 40: 209-227.

[4] Cowpertwait, P. S. P., O'Connell, P. E., Metcalfe, A. V., Mawdsley, J. A. (1996): Stochastic point process modelling of rainfall. I. Single-site fitting and validation. Journal of Hydrology 175: 17-46.

[5] Davies, T. R., McSaveney, M. J. (2008): Principles of sustainable development on fans. Journal of Hydrology (New Zealand) 47: 43-65.

[6] De Scally, F. A., Owens, I. F., Louis, J. (2010): Controls on fan depositional processes in the schist ranges of the Southern Alps, New Zealand, and implications for debris-flow hazard assessment. - Geomorphology 122: 99-116.

[7] Glade, T. (2005): Linking debris-flow hazard assessments with geomorphology. Geomorphology 66: 189-213.

[8] Guzzetti, F., Reichenbach, P., Cardinali, M., Galli, M., Ardizzone, F. (2005): Probabilistic landslide hazard assessment at the basin scale. - Geomorphology 72: 272299.

[9] Hürlimann, M., Rickenmann, D., Medina, V., Bateman, A. (2008): Evaluation of approaches to calculate debris-flow parameters for hazard assessment. - Engineering Geology 102: 152-163.

[10] IUGS (International Union of Geological Sciences). (1997): Working group on landslides, committee on risk assessment, quantitative risk assessment for slopes and landslides: state of the art. - Proceedings of the International Workshop on Landslides Risk Assessment, Rotterdam, Netherlands: 3-12.

[11] Iverson, R. M. (1997): The physics of debris flows. - Reviews of geophysics 35(3): 245296.

[12] Iverson, R. M. (2014): Debris flows: behaviour and hazard assessment. - Geology today 30(1): $15-20$. 
[13] Jakob, M., Bovis, M., Oden, M. (2005): The significance of channel recharge rates for estimating debris-flow magnitude and frequency. - Earth Surface Processes and Landforms 30: 755-766.

[14] Jakob, M., Hungr, O. (2005): Debris-flow hazards and related phenomena. - Springer, Berlin.

[15] Liang, W. J., Zhuang, D. F., Jiang, D., Pan, J. J., Ren, H. Y. (2012): Assessment of debris flow hazards using a Bayesian Network. - Geomorphology 171: 94-100.

[16] Lin, J. W., Chen, C. W., Peng, C. Y. (2012): Kalman filter decision systems for debris flow hazard assessment. - Natural Hazards 60: 1255-1266.

[17] Liu, X. L., Zhang, S. L., Tang, C., Chen, M. (1993): A preliminary research on the model experiments of the risk range of debris fan. - Geographical research 12(2): 77-85. (In Chinese).

[18] Liu, K. F., Huang, M. C. (2006): Numerical simulation of debris flow with application on hazard area mapping. - Computational Geosciences 10: 221-240.

[19] Meyer, N. K., Schwanghart, W., Korup, O., Romstad, B., Etzelmüller, B. (2014): Estimating the topographic predictability of debris flows. - Geomorphology 207: 114125.

[20] Okunishi, K., Suwa, H. (2001): Assessment of debris-flow hazards of alluvial fans. Natural Hazards 23: 259-269.

[21] Raetzo, H., Lateltin, O., Bollinger, D., Tripet, J. P. (2002): Hazard assessment in Switzerland-Codes of Practice for mass movements. - Bulletin of Engineering Geology and the Environment 61: 263-268.

[22] Rickenmann, D. (1999): Empirical relationships for debris flow. - Natural Hazards 19: 47-77.

[23] Rickenmann, D. (2016): Debris-flow hazard assessment and methods applied in engineering practice. - International Journal of Erosion Control Engineering 9(3): 80-90.

[24] Takahashi, T. (2009): A review of Japanese debris flow research. - International Journal of Erosion Control Engineering 2(1): 1-14.

[25] Takahashi, T. (2014): Debris flow: mechanics, prediction and countermeasures. - CRC Press, London.

[26] Tang, C., Zhu, J., Chang, M., Ding, J., Qi, X. (2012): An empirical-statistical model for predicting debris-flow runout zones in the Wenchuan earthquake area. - Quaternary International 250: 63-73.

[27] Tsai, Y. F. (2006): Three-dimensional topography of debris-flow fan. - Journal of Hydraulic Engineering 132(3): 307-318.

[28] Tsai, M. P., Hsu, Y. C., Li, H. C., Shu, H. M., Liu, K. F. (2011): Application of simulation technique on debris flow hazard zone delineation: a case study in the Daniao tribe, Eastern Taiwan. - Natural Hazards and Earth System Sciences 11: 3053-3062.

[29] Wei, F. Q., Hu, K. H., Lopez, J. L., Cui, P. (2003): Method and its application of the momentum model for debris flow risk zoning. - Chinese Science Bulletin 48(6): 594-598.

[30] Welsh, A., Davies, T. (2011): Identification of alluvial fans susceptible to debris-flow hazards. - Landslides 8: 183-194.

[31] Wilford, D. J., Sakals, M. E., Innes, J. L., Bergerud, W. A. (2004): Recognition of debris flow, debris flood and flood hazard through watershed morphometrics. - Landslides 1 : 61-66.

[32] Yu, B., Zhu, Y., Wang, T., Chen, Y. J., Zhu, Y. B., Tie, Y. B., Lu, K. (2014): A prediction model for debris flows triggered by a runoff-induced mechanism. - Natural hazards 74: 1141-1161. 